\title{
Mulheres Pela PerSPeCtiva MASCULINA NA LITERATURA JAPONESA: AS PROTAGONISTAS-NARRADORAS DE DAZAI ${ }^{1}$
}

\author{
Karen Kazue Kawana ${ }^{2}$ \\ Universidade de São Paulo
}

Resumo:

Desde o século X, a literatura japonesa possui várias obras em que o homem assume a narração que protagoniza uma mulher, portanto, o fato de Dazai Osamu1 (1909-1948) escrever contos com protagonistas-narradoras na segunda metade do século XX não é algo novo, entretanto, neste artigo, procuramos mostrar que elas possuem
Palavras-chave:

Mulheres, Narradoras, Literatura Japonesa, Dazai Osamu, Kawabata Yasunari, Tanizaki Jun'ichirô.

\section{Abstract:}

Since the 10th century, there are many literary works in the Japanese Literature in which we find male authors employing female protagonists as narrators, therefore, there is nothing new in Dazai Osamu (1909-1948) doing the same thing in the first half of the 20th, however, in this article, we try to show that his female protagonists have some characteristics that distinguish them from the female figures from the works of contemporaries like Kawabata Yasunari and Tanizaki Jun 'ichirô.

\section{Keywords:}

\author{
Women, Female \\ Narrators, Japanese \\ Literature, Dazai \\ Osamu, Kawabata \\ Yasunari, Tanizaki \\ Jun'ichirô.
}

\footnotetext{
${ }^{1} \mathrm{O}$ presente artigo, com algumas modificações, constitui parte da dissertação de mestrado intitulada "Reflexões sobre a mulher no Japão e nos textos de Dazai Osamu" defendida em novembro de 2015 junto ao Programa de Pós-Graduação em Língua, Literatura e Cultura Japonesa da Faculdade de Filosofia, Letras e Ciências Humanas da Universidade de São Paulo. ${ }^{2}$ Mestre em Língua, Literatura e Cultura Japonesa pela Faculdade de Filosofia, Letras e Ciências Humanas da Universidade de São Paulo e doutora em Filosofia pelo Instituto de Filosofia e Ciências Humanas da Unicamp, kawanakk@uol.com.br
} 
É comum que autores do sexo masculino escrevam textos nos quais a narração é feita por uma protagonista. Também é comum que os méritos e deméritos de tais textos sejam julgados conforme suas figuras femininas representem mais as preferências e fantasias do próprio autor - um estereótipo do feminino - do que uma mulher real. Nesse sentido, procuramos mostrar como as protagonistas-narradoras dos textos de Dazai Osamu seriam diferentes das figuras femininas presentes nas obras de escritores como Kawabata Yasunari e Tanizaki Jun'ichirô ao representarem mulheres, por assim dizer, mais verossímeis do que aquelas descritas nas obras destes últimos.

O Diário de Tosa (Tosa Nikki), atribuído ao poeta do período Heian (794-1185) Ki no Tsurayuki (872?-945), foi escrito por volta de 935 e é conhecido como o primeiro diário escrito em silabário kana. $^{3}$

Tsurayuki foi nomeado governador da província de $\mathrm{Tosa}^{4} \mathrm{em} 930$ e o diário teria sido escrito após o término de seu mandato de cinco anos. Nele, Tsurayuki descreve o retorno de barco da província para a capital, Quioto. Apesar dos acontecimentos serem semelhantes às experiências do próprio autor, ele escolhe uma das criadas de seu séquito para narrá-las. Alguns estudiosos consideram que a escolha de uma mulher como narradora seria um modo de criar uma forma nova e mais literária de diário, pois, até então, ele era um texto formal e burocrático escrito por homens.

O Diário de Tosa é considerado o pioneiro do gênero que posteriormente ficou conhecido como "literatura de diário" (nikki bungaku), no qual estão incluídos o Diário da Libélula (Kagerô Nikki, 974), o Diário de Lady Murasaki (Murasaki Shikibu Nikki, 1008-1010), o Diário de Sarashina (Sarashina Nikki, 1020-1059), entre outros. Estes realmente escritos por mulheres.

Alguns veem a escolha de uma figura ficcional feminina como narradora como um modo de o autor evitar críticas, pois seu diário frequentemente caracteriza as pessoas e os costumes de maneira irônica. Outros estudiosos acreditam que ele escolheu uma mulher porque as expressões de dor e perda não seriam apropriadas para um homem de sua posição. Ainda há aqueles que pensam que Tsurayuki assumiu uma figura feminina para poder escrever em kana, o que lhe daria maior liberdade de criação literária. Seja como for, o Diário de Tosa evita as convenções dos diários de corte da época. Ao invés de cerimoniais e detalhes administrativos, ele traz poesia, a descrição de eventos corriqueiros, expressa a dor da perda de entes queridos, relata o tédio, as dificuldades da viagem e a melancolia de chegar à casa dilapidada pelo tempo e pela falta de cuidados.

Segundo Okuno Takeo, no Japão, desde as Crônicas dos Acontecimentos Antigos (Kojiki ${ }^{5}$ ), são as mulheres que contam as histórias tradicionais, escrevem e leem diários:

Ki no Tsurayuki, o autor do primeiro diário escrito em kana, o Diário de Tosa, era um homem. No entanto, ele assumiu a persona de uma mulher, afirmando a intenção de "produzir um daqueles diários que dizem que os homens escrevem". Tais exemplos confirmam a percepção de que as mulheres são, ao mesmo tempo, mais capazes de escrever sem inibição sobre o cotidiano e mais aptas a expressar o romance e a emoção. ${ }^{6}$ (OKUNO, 1974 apud COPELAND, 2006, p. 68-69, tradução nossa)

Em Mulheres (Jorui, 1948), Dazai escreve que as categorias de ser humano e macaco são inadequadas para descrever as mulheres, pois elas são incompreensíveis e não poderiam ser classificadas como pertencendo a uma delas. Ôba Yôzô, personagem do romance Declínio de um Homem (Ningen Shikkaku, 1948), escrito por Dazai, também diz algo semelhante: "Sempre achei a fêmea da espécie humana

\footnotetext{
${ }^{3}$ Forma de escrita silábica japonesa. Até então, os diários eram escritos usando ideogramas chineses.

${ }_{5}^{4}$ Atual província de Kochi na ilha de Shikoku.

${ }^{5}$ Obra compilada por Ô no Yasumaro no início do século VIII que traz uma coleção de mitos sobre a origem do Japão e de seus deuses.

${ }^{6}$ OKUNO, T. Shôsetsu wa honshitsuteki ni josei no mono ka? (Is Fiction Inherently the Realm of Women?) in Jory $\hat{u}$ Sakka Ron. S.L: Daisan bunmeisha, p 9-15. (Translated by Barbara Hartley).
} 
muito mais difícil de compreender do que o macho.” (p. 38, tradução nossa). Elas eram cruéis e faziam com que sofresse, por outro lado, elas sempre se preocupavam com ele e permaneciam ao seu lado: “[...] minha conclusão era que, embora as mulheres parecessem pertencer à mesma espécie do homem, de fato, elas eram criaturas bastante diferentes, e esses seres incompreensíveis e insidiosos, por mais fantástico que pareça, sempre cuidaram de mim.” (DAZAI, 1948, p. 38-39)

Apesar da perplexidade de Dazai em relação às mulheres, entre algumas de suas melhores obras estão aquelas em que ele assume a persona de uma mulher e escreve em primeira pessoa. Os contos narrados por protagonistas são: A Luminária (Tôrô, 1937), A Estudante (Joseito, 1939), As Tenras Folhas da Cerejeira e o Assobio Misterioso (Hazakura to Mateki, 1939), Pele e Coração (Hifu to Kokoro, 1939), Sem que Ninguém Saiba (Daremo Shiranu, 1940), O Gafanhoto (Kirigirisu, 1940), Chiyojo (1941), A Humilhação (Haji, 1942), Oito de Dezembro (Jûnigatsu Yôka, 1942), À Espera (Matsu, 1942), Conto de uma Noite de Neve (Yuki no Yoru no Hanashi, 1944), A Cédula (Kahei, 1946), A Esposa de Villon (Villon no Tsuma, 1947), Osan (1947), Madame Hospitalidade (Kyôô Fujin, 1948); e o romance Pôr do Sol (Shayô, 1947).

Suas protagonistas são adolescentes, jovens mulheres, esposas e mães. Elas descrevem seu cotidiano, contam incidentes que as marcaram de alguma forma, falam sobre suas emoções, expectativas e dúvidas. O desejo de afirmação pessoal e o questionamento dos valores estabelecidos são algumas características presentes nesses textos.

As adolescentes de $A$ Estudante e Chiyojo tratam das inseguranças e da rebeldia típica dessa fase da vida. Elas criticam os adultos e os valores que a sociedade espera que elas observem. Seu desejo de liberdade choca-se contra as expectativas externas.

O desejo de afirmação de liberdade também está presente no conto $O$ Gafanhoto, no qual uma jovem mulher explica ao marido porque deseja deixá-lo. Ela o escolhera e fora viver com ele por conta própria, contrariando a vontade da família, porque o admirava. Ele era o pintor pobre, sem desejos mundanos, dedicado apenas à sua arte. Ela o via quase como um santo e estava disposta a fazer tudo por ele. No entanto, o marido torna-se um sucesso e transforma-se em um ser vaidoso e vão. A decepção da esposa é grande e a convivência com alguém que passa a desprezar, ao final, torna-se insuportável. Ela não se importava com aquilo que o mundo chamava de sucesso, com bens materiais e fama. Era feliz no início do casamento, quando eram pobres, tudo o que gostaria era de “... viver discretamente, com um orgulho enorme e altivo dentro do peito.” (DAZAI, 1940, p. 19, tradução nossa)

A valorização da individualidade é ressaltada nos textos do pós-guerra como A Esposa de Villon (Villon no Tsuma, 1947), Osan (1947) e Pôr do Sol (Shayô,1947). Neles, temos mulheres que passaram por experiências dolorosas, mas que se mostram capazes de superar as dificuldades e de tomar decisões sobre suas próprias vidas sozinhas, mesmo que isso contrarie a "moral e os bons costumes".

Sachan, a protagonista de A Esposa de Villon, é casada com um poeta que passa a maior parte do tempo em bares ou na companhia de outras mulheres, no entanto, ela lhe é fiel e, quando ele é acusado de roubar o dinheiro de um restaurante, ela se oferece para trabalhar no estabelecimento até que a dívida seja paga. Essa nova atividade lhe dá ânimo e Sachan decide continuar trabalhando mesmo depois que isso ocorre. Tudo parece ir bem até que ela é estuprada por um freguês do restaurante. Quando encontra o marido lendo o jornal logo após esse incidente, ele lhe diz que não é um monstro e que roubara porque desejava comemorar o Ano Novo com a família. A reação de Sachan é um dar de ombros resignado: 


\begin{abstract}
- Ah, estão falando mal de mim outra vez. Dizem que sou um falso nobre epicurista. Isso não é verdade. Podiam ter escrito que sou um epicurista que teme a deus. Satchan, veja! Escreveram que sou um monstro. Isso não é verdade, não é mesmo? Conto isso agora, mas, no final do ano passado, saí daqui com os cinco mil ienes porque desejava que você e o menino tivessem um Ano Novo memorável. Fiz aquilo porque não sou um monstro.

- Que mal há em ser um monstro? Se estivermos vivos, isso já é o suficiente - disse com indiferença. (DAZAI, 1947, p. 53-54, tradução nossa)
\end{abstract}

Em Osan, temos outra esposa. Seu marido tem uma amante com quem, por ser incapaz de sustentar a situação diante da família, comete suicídio.

Ao ouvir o hino nacional francês poucos dias antes de se matar, ele se emocionara, chorara e dissera que a destruição era necessária em uma revolução. Era preciso destruir a ordem existente para que algo novo surgisse em seu lugar. Por isso as revoluções eram tristes e belas. Ao dizer aquilo, ele associara a destruição da monarquia francesa à destruição da harmonia familiar. Mas a sua ideia de revolução conduzia apenas à destruição, sem que nada novo surgisse. Para a esposa, aquele tipo de revolução não tinha sentido:

A revolução serve para que as pessoas possam ser felizes. Não confio em revolucionários trágicos. Por que ele não pôde amar essa mulher de modo mais explícito e prazeroso, e, ao mesmo tempo, amar e fazer sua esposa, eu, feliz? (DAZAI, 1947, p. 29)

Em ambos os textos, as mulheres não se preocupam com a opinião alheia, com a moralidade ou ideologias. Elas são livres, enquanto isso, os homens são presas de suas próprias quimeras. As preocupações femininas são mais concretas. Os homens são incapazes de confrontar a realidade e agir de forma prática, as mulheres são mães e precisam cuidar de sua manutenção e a dos filhos, morrer está fora de questão para elas.

Em Pôr do Sol (Shayô, 1947), Kazuko, a protagonista e narradora, descreve sua própria revolução e luta contra os valores da sociedade. Filha de nobres que perderam tudo em um mundo em transição no pós-guerra, ela decide seduzir e ter um filho com um escritor decadente, ela será tratada como uma pária por sua ousadia, mas não se importa com isso.

Apesar de suas figuras femininas marcantes e fortes, Dazai não pode ser considerado um feminista. Em Igualdade entre Homens e Mulheres (Danjo Dôken, 1946), ele escreve sobre a nova constituição que estabelece a igualdade de direitos entre homens e mulheres no Japão com humor e também com um tom crítico. No texto, um palestrante não pôde participar de uma conferência educativa e um velho poeta é convidado a falar em seu lugar. O tema que escolhe é exatamente esse: a igualdade de direitos entre os sexos. Ele fala sobre a sua vida e sobre o sofrimento que experimentou nas mãos das mulheres desde a infância até a velhice. Sua conclusão é inesperada: agora que há igualdade de direitos, ele tem a liberdade de denunciar os maus-tratos sofridos em silêncio nas mãos femininas. As mulheres não poderiam mais recorrer à desculpa de que pertenciam ao "sexo frágil".

Apesar da conclusão cômica, o Dazai do pós-guerra realmente parecia considerar as mulheres fortes, como diz o marido da peça Folhas Secas de Primavera (Haru no Kareha, 1946) à esposa que o segue em determinado silêncio: 
[...] você é forte [...] Perdi, perdi. Fui derrotado. Mas de onde vem essa sua força? Ela não tem qualquer relação com a igualdade entre os sexos. Desse jeito, os homens é que precisam pedir socorro. Mas qual é a natureza dessa força? E besteira falar em feudalismo ou conservadorismo. Acho que não é um fato histórico. Vocês já possuíam essa força desde a pré-história. E, enquanto a humanidade existir na terra, não, enquanto existirem animais, vocês serão eternamente fortes. (p. 64, tradução nossa)

Mesmo tendo crescido em um ambiente com valores antigos e padrões de comportamento feudal, Dazai não parece considerar as mulheres inferiores, ao contrário, talvez devido ao seu sentimento de inferioridade e também de culpa em relação a elas, as mulheres surgem em seus textos como figuras movidas pelo desejo de viver. Mas ele não é o único a descrevê-las dessa forma. O crítico Akiyama Shun escreve algo parecido sobre a dificuldade de compreender as mulheres e sobre a sua força:

[...] achava as fêmeas (mulheres, se preferir) um tanto estranhas. Elas pareciam ser criaturas de tipos diferentes, levando diferentes tipos de vida.

Falta às mulheres a aura de morte, elas possuem poucas tendências niilistas, uma impressão que talvez se deva à minha inexperiência. No entanto, me parece que elas se entregam muito à vida e desejam-na em demasia. Por mais estranho que pareça, as mulheres persistem e sobrevivem mesmo quando parece inumano fazê-lo, uma vez que a premissa de sua existência é uma afirmação da vida. Em termos de desejo de viver, os homens, em comparação, são essencialmente fracos. ${ }^{7}$ (AKIYAMA, 1976 apud COPELAND, 2006, p. 74, tradução nossa)

Dazai provavelmente concordaria com a opinião de Akiyama, as figuras masculinas que surgem em seus textos são niilistas e fracos, enquanto suas mulheres se agarram à existência com resolução apesar das circunstâncias adversas.

Segundo Okuno Takeo ${ }^{8}$ (1974 apud COPELAND, 2006, p. 69), os princípios masculinos seriam dominantes durante a guerra, e os temas da literatura da época estariam igualmente centrados em assuntos políticos e econômicos. No pós-guerra, os valores patriarcais entraram em colapso e, para autores como Dazai, não havia mais crenças em ideais de revolução política, ética ou no progresso da humanidade. Restava o niilismo e a passividade. A desmoralização masculina teria dado, assim, lugar à força feminina.

As protagonistas de A Esposa de Villon (Villon no Tsuma, 1947), Osan (1947) e Pôr do Sol (Shayô, 1947), obras escritas por Dazai no pós-guerra, tomam decisões na ausência de uma figura masculina na qual possam encontrar apoio. Nelas, Dazai passa o bastão às mulheres. A figura masculina sucumbe, incapaz de se adequar aos valores do mundo que surge das ruínas da guerra, mas, para o autor, as mulheres conseguiriam se adaptar e sobreviver. Elas não lamentariam a perda de um passado tradicional ou a derrota na guerra, não temeriam as mudanças, seriam capazes de fazer a síntese entre o tradicional e o moderno para criar algo novo.

Os textos com protagonistas-narradoras de Dazai revelam uma grande sensibilidade e capacidade de observação dos hábitos e questões femininas. E, como seu predecessor no gênero, Ki no Tsurayuki, suas protagonistas também se mostram minuciosas observadoras do corriqueiro, dos acontecimentos e fatos próximos. Sua narração, como escreve Gilda de Mello e Souza, é a dos míopes:

\footnotetext{
${ }^{7}$ AKIYAMA, S. Joryû bungaku no Tôwaku (Confessions of a women's literature convert) in Kokugungaku kaishaku to kyôzai kenkŷ̂. S.1., Jul. 1976, p. 14-17. (Translated by Barbara Hartley).

${ }^{8}$ OKUNO, T. Shôsetsu wa honshitsuteki ni josei no mono ka? (Is Fiction Inherently the Realm of Women?) in Joryû Sakka Ron. S.1: Daisan bunmeisha, p. 9-15. (Translated by Barbara Hartley).
} 
Não será difícil apontar na literatura feminina a vocação da minúcia, o apego ao detalhe sensível na transcrição do real, características que, segundo Simone de Beauvoir, derivam da posição social da mulher. Ligada aos objetos e deles dependendo, presa ao tempo, em cujo ritmo se sabe fisiologicamente inscrita, a mulher desenvolve um temperamento concreto e terreno, movendo-se como coisa num universo de coisas, como fração de tempo num universo temporal. A sua é uma vida refletida, sem valores, sem iniciativa, sem acontecimentos de relevo, e os episódios insignificantes que a compõem, de certo modo só ganham sentido no passado, quando a memória, selecionando o que o presente agrupou sem escolha, fixa dois ou três momentos que se destacam em primeiro plano. Assim, o universo feminino é um universo de lembrança ou de espera, tudo vivendo, não de um sentido imanente, mas de um valor atribuído. E como não lhe permitem a paisagem que se desdobra para lá da janela aberta, a mulher procura sentido no espaço confinado em que a vida se encerra: o quarto com os objetos, o jardim com as flores, o passeio curto que se dá até o rio ou a cerca. A visão que constrói é por isso uma visão de míope, e no terreno que o olhar baixo abrange, as coisas próximas adquirem uma luminosa nitidez de contornos. (1980, p. 79)

Claro que Dazai é um homem se "travestindo" de mulher, não uma escritora como Clarice Lispector, a quem Gilda de Mello e Souza se refere no trecho acima, mas feita essa ressalva, a narrativa de Dazai não deixa a desejar, e seu travestimento - no sentido de emular esse "olhar de míope" feminino, limitado aos objetos próximos e a um universo interno composto de sentimentos, memória e sensações - é quase completo. Suas protagonistas movem-se em um "universo de coisas", revelam "apego ao detalhe na transcrição do real". Só não podemos dizer que elas permaneçam sempre "sem valores", pois, muitas vezes, servem de porta-vozes para as ideias, críticas e angústias do autor em relação à sociedade. E, em seus textos do pós-guerra, elas tomam cada vez mais a iniciativa em relação a suas vidas e se encaminham para uma afirmação pessoal.

Segundo Satô Akemi (2001), Dazai se mostrou tal como era em seus textos confessionais da juventude, porque desejava ser honesto e sincero, esses eram textos de sua fase "romântica", no entanto, a recepção não foi a esperada e ele acabou sendo criticado por autores que admirava como Kawabata Yasunari. Quando expôs a si mesmo e todas as suas fraquezas, o que encontrou não foi compreensão e simpatia, mas repreensão. Essa experiência teria feito com que Dazai procurasse uma forma de se expressar que não envolvesse um confronto ou antagonismo com os valores estabelecidos, um modo de expressar o que sentia que não ferisse sensibilidades. Para isso, ele deveria:

[...] conseguir se expressar passivamente, ao invés de conceitos, a carne; ao invés da lógica, a fisiologia; ao invés da razão, a sensibilidade [...] Como resultado, a técnica da fala feminina mostrou-se apropriada para expressar as emoções de Dazai, o pária da sociedade, e ele recebeu o apoio de muitos leitores. (SATÔ, 2001, p. 74, tradução nossa)

Apesar de considerar as mulheres incompreensíveis, Dazai teria concluído que, se ele realmente desejava dar vazão a seus sentimentos e recriar o conteúdo do cotidiano em todos os seus detalhes, ele só o poderia fazer como uma mulher.

Os protagonistas masculinos das obras de Dazai são todos muito parecidos com Ôba Yôzô, do romance Declínio de um Homem (Ningen Shikkaku, 1948), alter egos do próprio autor. Sem confiança em si mesmos e sem autoestima, sentindo-se hostilizados pelo mundo e impotentes diante de seu próprio desespero. Eles revelam muito sobre si mesmos, exageram faltas e defeitos. Tentam superar seu isolamento por meio da sinceridade e da confissão e tornam-se patéticos aos olhos da própria sociedade diante da qual procuram se justificar. Quando falham, fazem uso de imposturas, ou recorrem à crueldade. São 
aterrorizados pela imagem de um deus vingativo. Tornam-se presas do negativismo e procuram se libertar por meio do suicídio ou de vícios.

Por meio de protagonistas femininas, portanto, Dazai fugiria dessa imagem negativa transmitida dos protagonistas masculinos para si próprio. E, apesar de elas também recorrerem à confissão para se expressarem, como a sinceridade e a emoção ser-lhes-iam naturais, elas não precisariam justificar seus sentimentos ou ações, não seriam julgadas e criticadas da mesma forma que os protagonistas masculinos. Nesse sentido, seriam muito mais livres do que eles, com a vantagem de não serem diretamente associadas ao autor.

Os textos com protagonistas-narradoras, começando com A Estudante (Joseito, 1939), constituem um gênero à parte na obra de Dazai. $O$ travestimento seria ainda maior devido ao próprio estilo de escrita do autor, com poucos verbos e frases fragmentadas, ideias interrompidas e retomadas em seguida. Quando Dazai faz com que suas protagonistas se expressem dessa forma, ele conferiria naturalidade à maneira como elas expressam sentimentos e sensações (OKAZAKI, 1996).

No imaginário do leitor ocidental, as figuras femininas da literatura japonesa ficaram marcadas como as mulheres dóceis e passivas vestidas de quimono, como aquelas da obra de Kawabata Yasunari, ou como as jovens atraentes e misteriosas que despertam as fantasias masculinas, como Naomi de Amor Insensato (Chijin no Ai, 1925), de Tanizaki Jun'ichirô.

Segundo Kobayashi Hideo, Kawabata Yasunari seria o autor contemporâneo com tendências feministas mais claras. No entanto, apesar de descrever mulheres e seu comportamento com sensibilidade, ele não as descreveria tais como elas existem na realidade:

Por exemplo, na recente obra-prima de Kawabata, O País das Neves, que tipo de gueixa do país das neves ele descreve? A beleza daquela gueixa, na verdade, não é nada mais do que a beleza que o próprio autor deseja, e é a habilidade do autor como escritor que nos faz acreditar que tal mulher possa realmente existir. Ou seja, a beleza da protagonista é a beleza vista pelo coração masculino do autor, as mulheres nunca poderiam realmente ter uma imagem semelhante de seu próprio sexo. ${ }^{9}$ (KOBAYASHI, 1977 apud COPELAND, 2006, p. 50, tradução nossa)

As mulheres nas obras de Kawabata seriam, assim, filtradas pelo olhar masculino. Visões de beleza que compõem cenários e enriquecem suas descrições. Não seriam muito diferentes de objetos aos quais se atribuem valores estéticos. Em Mil Grous (Senbazuru), romance de 1949, um jarro em cerâmica evoca a beleza e a sensualidade feminina:

Um vermelho pálido pairava sobre o esmalte branco. Kikuji estendeu a mão para tocar sua superfície lustrosa e calidamente fria.

- Suave, como um sonho. Mesmo eu aprecio um bom Shino.

"Suave, como sonhar com uma mulher", ele pensou, mas suprimiu as últimas palavras. (1967, p. 48, tradução nossa)

Em outro momento, na mesma obra, as qualidades do jarro são comparadas com a senhora Ôta, antiga amante do protagonista:

\footnotetext{
${ }^{9}$ KOBAYASHI, H. Joryû Sakka in Kindai bungaku shisô taikei 29 Kobayashi Hideo shû. S.l.: Chikuma Shobô, 1977. p.
} 46-50. Originalmente publicado em janeiro de 1938. (Translated by Kathry Pierce and Mika Endo). 
Mesmo a superfície do Shino, com um cálido brilho frio, fez com que ele pensasse na Senhora Ôta. Provavelmente devido ao refinamento da peça, a lembrança estava livre da escuridão e deformidade da culpa.

Enquanto observava a obra-prima que o jarro era, ele começou a sentir que a senhora Ôta fora uma obra-prima como mulher. Em uma obra-prima, não havia nada impuro. (KAWABATA, 1967, p. 89)

Em Kawabata, objetos e mulheres são imbuídos de sensualidade e se confundem. Ele se esmera em detalhar o exterior, os gestos, a aparência e as roupas das mulheres, ou seja, a forma feminina, mas não a sua substância.

Em um diálogo de 1978, as escritoras Takahashi Takako (1932-2013) e Tsushima Yûko ${ }^{10}$ (1947) criticam a forma como os autores japoneses caracterizam as mulheres em suas obras. Segundo Takahashi, da perspectiva feminina, as mulheres de Kawabata não são mulheres reais e, mesmo que não sejam necessariamente falsas, seriam insubstanciais, uma falta comum nas mulheres descritas por autores do sexo masculino:

A beleza das mulheres que Kawabata cria parece ilusória para uma mulher, mas é a beleza feminina tal como ela aparece para os olhos masculinos, portanto, nesse sentido, não se pode negar sua validade. Esse tipo de imagem feminina não é peculiar à ficção de Kawabata Yasunari; ela é típica da literatura de muitos autores do sexo masculino [... $]^{11}$ (TAKAHASHI; TSUSHIMA, 1978 apud COPELAND, 2006, p. 120 , tradução nossa)

No entanto, mesmo que as descrições das mulheres na obra de Kawabata e em outros autores não seja condizente com a realidade, elas são belas. Isso confere valor literário às obras e não as desmerece:

As mulheres de Kawabata Yasunari parecem usar máscaras, e é como se essas máscaras fossem observadas pelo olhar masculino. Mas aquilo que está atrás da máscara não é descrito. Não estou dizendo que esse tipo de descrição seja inadequada; acho que não há nada a ser feito. Há beleza na máscara e a literatura é criada por meio desse tipo de beleza, então, esse modo de representação tem seu mérito apesar de tudo. Talvez não seja razoável esperar mais do que isso dos autores do sexo masculino. (TAKAHASHI; TSUSHIMA, 1978 apud COPELAND, 2006, p. 120)

As mulheres na ficção passam pelo filtro do olhar e das fantasias masculinas, por isso, elas não parecem reais para outras mulheres, mas isso não diminuiria o valor de uma obra literária. Para Takahashi, o fato de a maior parte dos leitores de Kawabata ser composta de mulheres revela apenas que suas leitoras também vestem uma máscara e o leem como se vissem a si mesmas como objeto do olhar masculino. Elas desejam ser consideradas belas pelos homens e ler autores como Kawabata satisfaria, assim, seu narcisismo.

No outono de 1989, três intelectuais - Ueno Chizuko (1948), Ogura Chikako (1952) e Tomioka Taeko (1935) - se encontraram para discutir o tema "o homem como escritor". Seus encontros se estenderam por sete meses e resultaram no livro Sobre a Literatura Masculina (Danryû Bungakuron, 1992). Não se trata de algo inédito, as mulheres sempre criticaram e estudaram os autores masculinos, afinal, os homens estão presentes em maior número no panteão literário japonês. E, como acabamos de ver no diálogo de Takahashi Takako e Tsushima Yûko, também não era a primeira vez que mulheres se sentavam para discutir a escrita masculina. No entanto, desta vez o debate era motivado por um desejo consciente de submeter a literatura feita por homens a uma leitura de gênero. Para começar, as três apontam para o fato de que a "linguagem masculina" e o falocentrismo estariam tão imbuídos na crítica literária que passariam despercebidos dos leitores.

\footnotetext{
${ }^{10}$ Pseudônimo de Satoko Tsushima, segunda filha de Dazai Osamu e Ishihara Michiko.

${ }^{11}$ TAKAHASHI, T.; TSUSHIMA, Y. Onna no sei to otoko no me (Female sexuality and the male gaze) in Waseda Bungaku 30 (11), Nov. 1978, p. 4.14. (Translated by Maryellen Toman Mori).
} 
A informalidade e a linguagem coloquial da discussão fizeram com que alguns críticos considerassem suas análises infantis (COPELAND, 2006, p. 206-209). No entanto, as obras e autores discutidos em cada encontro não eram escolhidos ao acaso. As discussões envolviam planejamento e as discussões visavam questionar os critérios que davam maior reconhecimento a um autor do que a outro.

Os críticos questionavam quais eram as qualificações das debatedoras para julgar escritores canônicos como Tanizaki Jun'ichirô, Mishima Yukio, Murakami Haruki, etc. Ogura Chikako tinha um doutorado em psicologia pela Universidade de Waseda e era conhecida por seus estudos sobre gênero e cultura contemporânea. Ueno Chizuko era uma intelectual conhecida por discutir tópicos tão diversos quanto leis laborais e arte gráfica. Todos os seus trabalhos continham um viés feminista. Tomioka Taeko, por sua vez, era a única escritora do grupo e, na época, já era conhecida como poeta, roteirista, romancista e ensaísta.

Apesar das controvérsias, as discussões tinham o mérito de indicar as limitações da perspectiva masculina e, assim, aumentar a consciência dos leitores sobre aquilo que liam. Afinal, até então, as obras eram julgadas de acordo com valores masculinos e agora elas eram analisadas por mulheres.

Quando discutem os textos de Tanizaki Jun'ichirô, as três acreditam que o autor coloca muita ênfase na sexualidade e comparam-no a Henry Miller ${ }^{12}$ (1891-1980), autor que mistura autobiografia, linguagem explícita, sexo e misticismo. Segundo Ueno, Tanizaki representa as mulheres apenas em termos de categoria:

A Chave $[$ Kagi, 1956] é o mais típico exemplo disso. O estilo em que o diário da esposa é escrito é extremamente artificial para uma mulher. Itô Sei criticou o autor por projetar a si mesmo de forma muito óbvia no modo da mulher se expressar no romance. Por exemplo: "Ao voltar a ser uma esposa virtuosa e submissa, posso gratificar meu grande apetite sexual". Uma mulher nunca escreveria algo parecido em seu diário. "Sou o tipo de pessoa em cujo coração luxúria e timidez coexistem" e assim por diante..$^{13}$ (OGURA; TOMIOKA; UENO apud COPELAND, 2006, p. 214-215, tradução nossa)

Trechos como os citados acima não seriam coisas que uma mulher diria e apontariam para a perspectiva de uma terceira pessoa, ou seja, o autor. Haveria uma grande diferença entre dizer "eu sou libidinosa" e "ela é libidinosa", segundo Ueno, uma mulher nunca diria algo parecido sobre si mesma enquanto a segunda alternativa é perfeitamente aceitável, mas fazer a personagem dizer isso em primeira pessoa, como Tanizaki faria, soaria artificial, revela que o autor cria uma alegoria feminina, um tipo feminino, e faz com que ela se expresse como ele a imagina fazendo sem se importar com a inadequação da linguagem.

As mulheres de Tanizaki constituiriam uma categoria, seriam "tipos". Como as mulheres nas obras de Kawabata Yasunari, elas também não seriam mulheres reais:

Ogura: Seja Matsuko, Mitsuko ou Naomi, todas as mulheres de Tanizaki se parecem umas com as outras, não é verdade? Nenhuma delas possui as habilidades que uma mulher comum normalmente adquire quando se torna adulta. (OGURA; TOMIOKA; UENO apud COPELAND, 2006, p. 218)

As mulheres do autor dariam a impressão de não possuírem competências humanas ou uma individualidade. Elas não tomariam decisões práticas, analisariam situações ou agonizariam entre escolhas possíveis. Apesar de sua escrita vívida, suas mulheres não passariam de estereótipos:

\footnotetext{
${ }^{12}$ Escritor americano, autor de Trópico de Câncer (1934) e Trópico de Capricórnio (1939).

${ }^{13}$ OGURA, C.; TOMIOKA, T.; UENO, C. Selections from chapter 3, Tanizaki Jun'ichirô: Quicksand and Naomi in Danryû bungaku. S.l.: Chikuma Shobô, 1992, p. 136-185. (Translated by Maryellen Toman Mori).
} 
Tomioka: Tanizaki geralmente escrevia de um modo tão concreto e realista. Sua prosa não é superficial; é rica e densa em textura. Mas tão logo ele começava a descrever uma mulher, ele recorria a estereótipos. É tão irritante, não é mesmo? Realmente gostaria que ele retratasse mulheres com mais profundidade. (OGURA; TOMIOKA; UENO apud COPELAND, 2006, p. 223)

No entanto, as três concordam que se uma mulher quebrasse o molde no qual o autor a enforma, o universo de seus textos entraria em colapso. Elas serviriam ao fim de sua ficção e qualquer coisa que se desviasse do estereótipo criado por ele, faria com que seus textos perdessem seu prumo. Mas isso não se restringiria a Tanizaki. As mulheres retratadas nos textos masculinos quase sempre seriam estereotipadas e, mesmo quando eram bem acabadas, pareciam sempre elusivas. Elas provavelmente desapareceriam se fossem submetidas a análises mais profundas.

As mulheres descritas por autores do sexo masculino fariam parte da categoria "mulher", sem qualquer individualidade. Seriam idealizações e serviriam para personificar a beleza, a sensualidade ou erotismo na obra do autor. Ueno lembra que o próprio Tanizaki escreveu que os autores do passado não se importavam com a personalidade de uma mulher ou com suas peculiaridades:

Vocês sabem que Tanizaki publicou um ensaio em 1931 intitulado "Amor e Luxúria". Nele, escreve: "As pessoas reclamam que as personalidades das mulheres nos romances do passado, desde o tempo dos Contos de Genji, parecem todas iguais; suas características individuais não são descritas. Mas os homens daqueles tempos não se apaixonavam pela personalidade única de uma mulher. Eles não eram cativados pelo adorável rosto de uma mulher ou pelo charme de seu corpo. Para eles, assim como a lua é sempre a mesma lua, a 'mulher' provavelmente era sempre uma e a mesma 'mulher'." Em outras palavras, ele está dizendo que ela era todas as mulheres, como uma categoria. "Na penumbra, ele ouviria o fraco murmúrio de sua voz, sentiria a fragrância de roupas de seda, acariciaria seus cabelos, tocaria sua pele úmida com a ponta dos dedos e, então, com o anúncio do amanhecer, todas aquelas sensações se desvaneceriam. Os homens do passado deviam considerar todos esses atributos em conjunto como a 'mulher'." Isso fica muito claro. Não é necessário distinguir as mulheres como indivíduos separados. (OGURA; TOMIOKA; UENO apud COPELAND, 2006, p. 234)

Os escritores japoneses continuariam a fazer o mesmo. Quando um homem descrevia uma mulher, não o faria como um indivíduo, mas como uma categoria mais ampla, a da "mulher" na qual as características individuais se dissolveriam. O que restaria, seriam as sensações que ela evocava no autor.

A categorização da mulher também fica evidente nas obras de Kawabata. Em um episódio de $O$ País das Neves (Yukiguni), romance serializado entre 1935-37, Shimamura pede que a jovem Komako chame uma gueixa. Ele queria satisfazer seu desejo por uma mulher, independente de quem ela fosse: "Seu desejo por uma mulher não era do tipo que o fizesse desejar aquela mulher em particular - era algo a ser executado com despreocupação e sem culpa.” (KAWABATA, 1996, p. 23, tradução nossa).

Como observamos em Mil Grous (Senbazuru), mãe e filha, antiga amante e a mulher pela qual Kikuji sente-se atraído, se misturam. As distinções deixam de existir e o que resta é a "mulher", a amante, quem ela seja não importa, qualquer particular é subsumido pela categoria. Quando Fumiko se apoia nele para não cair, ele tem "intensa consciência da mulher. Ele estava consciente da mãe de Fumiko, a senhora Ôta” (KAWABATA, 1967, p. 86) e, ao sentir o odor de Fumiko, ele se lembra da mãe desta última: 
$\mathrm{O}$ odor era forte. Ele o atingiu com vigor, o odor de uma mulher que estivera trabalhando desde a manhã até a tarde em um dia de verão. Ele sentiu o odor de Fumiko. O odor de sua mãe. O cheiro do abraço da senhora Ôta. (p. 86)

Apesar de serem duas mulheres distintas, as diferenças desaparecem e resta a mulher, no singular. As figuras femininas nas obras de Tanizaki e Kawabata se diferenciam por representarem tipos distintos, personagens como Naomi, do romance Amor Insensato (Chijin no Ai, 1925), escrito pelo primeiro, são exóticas por incorporarem aparência, hábitos e comportamentos ocidentais, o que as torna objeto de fascínio para os personagens masculinos de suas obras. Elas não são "ocidentais", mas se distinguem por traços físicos, maneirismos, estilo de vida e formas de pensar e agir que evocam o estrangeiro. Essas mulheres surgem, na obra de Tanizaki, como o símbolo da assimilação do Ocidente, do moderno, pela cultura japonesa. Elas ainda são “orientais", mas se distinguem da imagem da mulher japonesa moldada pelas convenções sociais e, por isso, podem assumir o papel de mulheres fatais na ficção japonesa. Segundo Indra Levy, Naomi pressagiaria o advento da "garota moderna", a "moga":

Sem dúvida, a mais conhecida dentre essas figuras é a Naomi de Amor Insensato [Chijin no $A i, 1925]$ de Jun'ichirô Tanizaki, uma jovem mulher que involuntariamente atrai o protagonista e narrador devido às ressonâncias ocidentais de seu nome e o conquista completamente por meio de sua performance ocidental calculada conscientemente, garantindo sua liberdade sexual por meio da escravização de seu parceiro. Vista no contexto da Tóquio dos anos 20, Naomi pressagiava o advento da Garota Moderna, aquele fenômeno urbano amplamente discutido na mídia de seu dia e que continua a fascinar tanto os historiadores culturais quando a imaginação popular. Quando considerada no interior da trajetória geral da história da literatura japonesa moderna, ela também pode ser inserida na genealogia que remonta à Nova Mulher do período Taishô, que compartilhava com a Garota Moderna, em sua marcada capacidade de personificar da forma mais provocativa, a última tendência da modernidade japonesa. (LEVY, 2006, p. 5, tradução nossa)

Enquanto isso, a mulher de Kawabata recuperaria o aspecto mais propriamente "tradicional" da cultura japonesa, geralmente passiva e submetida à família e aos valores da sociedade, mais um objeto a ser contemplado, desejado e admirado do que propensa à ação e à livre expressão de seus sentimentos. Kawabata reforça essa impressão ao inseri-la em um cenário com tradições, roupas e objetos típicos, quase uma exaltação do "oriental” em detrimento do "ocidental”.

As protagonistas-narradoras de Dazai, por sua vez, encontram-se em um meio-termo, elas não são "mulheres fatais" com traços ocidentais que as tornariam exóticas, nem seres passivos e submissos. Ao contrário das mulheres descritas por Kawabata e Tanizaki, elas não se parecerem com marionetes movimentadas de acordo com a vontade do autor. Não dão a impressão de representar idealizações de uma terceira pessoa. O autor não as constrói como "tipos" ou as inclui em uma categoria. Ao contrário, ele, por assim dizer, as encarna e, ao vestir mais essa máscara, aumenta a ilusão do imediato, pois suprime a sensação de que sua personagem não passa de uma marionete. Ele efetivamente torna-se a personagem. Nesse movimento, o artifício dá lugar à naturalidade.

Como vimos anteriormente, Satô Akemi acredita que Dazai passou a empregar mulheres como protagonistas-narradoras para conseguir se expressar evitando que sua escrita de estilo confessional e prenhe de arroubos emocionais se tornasse alvo de críticas. Escrever como uma mulher que, naturalmente já se expressaria de forma mais emocional e desconexa, passando de um sentimento a outro, de uma imagem a outra, daquilo que lhe ocorria no momento, nessa "visão de míope" que constituiria o modus operandi feminino de acordo com Gilda de Mello e Souza (1980), teria sido benéfico para a escrita de 
Dazai. E, mesmo que ele se deixasse entrever por baixo da máscara feminina quando tratava de assuntos que lhe eram muito próprios (como quando suas protagonistas falam sobre revolução ou mencionam a divindade), a ilusão não se perderia, porque não haveria de fato um artifício. Suas protagonistas não eram meras construções, elas eram o autor. A cisão entre autor e personagem deixaria, assim, de existir, a tal ponto que mesmo suas leitoras se identificavam com suas mulheres.

Dazai também não era alheio às questões e preocupações femininas do período e as incorpora a seus textos. Suas protagonistas mencionam revistas, penteados, canções e filmes, estão imersas em uma época e também vivem seus conflitos. Elas revelam alguns aspectos que poderiam ser considerados fúteis, mas também desejam afirmar sua individualidade. Desejam viver de acordo com suas próprias convicções e, mesmo tolhidas pelas expectativas e olhares dos outros, procuram estender seu campo de visão para além do espaço imediato.

Recebido em: 10/05/2016.

Aprovado em: 05/06/2016. 